have not been relieved because the physician has read of the dangers of the infusion of jequirity and has not heard of the powder, which, as I have before stated, I believe is free from danger.

This fear is the only apology I have to offer for reading a paper on this old and much written of subject, before this Section of the American Medical Association.

\section{A DANGER IN THE USE OF JEQUIRITY HERETOFORE UNMEN'TIONED.}

Read in the Section of Ophthalmology, at the Forty-first Annual Meeting of the American Medical Association, at Nashoille,

BY T. E. MURRELI, M.D., OF LITTLE ROCK, ARK.

I was one of the first to combat Sattler's theory of the bacterial origin of jequiritic conjunctivitis. I was making experiments with the bean, clinically and microscopically, about the time this theory was promulgated, and I had reasons for non-concurring. They were: First, the fresh infusion of jequirity was found to be more powerful than the old, and no bacteria could ever be found in the fresh infusion; second, in old infusions of the other leguminosæ similar bacteria were discovered, and in greater numbers than in the jequiritic infusion, and yet they were without effect on the conjunctiva. It is now well agreed that the peculiar property of jequirity resides in the bean and is not derived from any other source. Strange to say, however, this principle has never been isolated by the chemist. The infusion being perfectly bland, only possessing in a marked degree the narcotic odor belonging to the leguminosæ, it is a singular phenomenon that such striking changes should be produced in the vital functions of a mucous membrane by its topical application. Its tendency to clear out infiltrations and to dissolve adventitious structures renders it a remedy of great value in certain conditions of the eye.

While much difference of opinion exists as to its real merit as a therapeutic agent, and as to its proper field of usefulness, there can be no question as to its marked beneficial effect in some cases. We possess nothing superior for clearing corneæ densely opaque from inveterate pannus. A remedy so powerful is reasonably not without danger. Extensive posterior synechiæ have been discovered after clearing the cornea by its use, thus showing the danger to which the iris is exposed by its action; hence it is well to always guard against this accident by the free use of atropine so long as the artificially produced conjunctivitis continues. U1ceration of the cornea has also followed its action in improperly selected cases, but with reasonable care and judgment this danger can be reduced to a minimum.

Those who deal much with long standing and badly treated cases of granular conjunctivitis will now and then find one suitabie for the application of jequirity. As ophthalmic surgeon to the Arkansas School for the Blind I meet some such cases annually, and the results, I would also say parenthetically, are sometimes most gratifying.

As is well known, collyria dropped in the eyes often run through the tear passages and are tasted in the mouth. It occurred to me that the use of the infusion of jequirity in the eye might, by entering the lachrymal sac and nasal duct, excite similar inflammation in these parts, or in the nose even, as in the eye.

Such apprehensions have within the last year been fulfilled in three instances; two of them occurring in a young lady, involving the tear passages of both eyes, and the other in a young man in whom only the right tear passages were so affected. In each case the jequirity was used in a 2 per cent. infusion repeatedly dropped in the eyes with a pipette until severe inflammation ensued, which was then allowed to run its course unmolested. Each of these patients was carried through a second course of the jequirity treatment, and some time after recovering from the last course of treatment I found the young lady had a dacryocystitis of both lachrymal sacs, and the young man of the right sac only. Delaying in operating to overcome the strictures in the nasal ducts, acute phlegmon developed in the left sac of the young lady and in the right sac of the young man. The cases were treated in the usual way, the phlegmons opened externally, and when the swelling had sufficiently subsided the canaliculi were opened and afterwards the strictures overcome by the use of Bowman's probes, and the cases finally cured. There had never been any symptoms of trouble with the tear passages prior to the use of the jequirity, and neither case had nasal trouble; hence the inference is clear that we here had jequiritic inflammation of the mucous membrane lining the lachrymal sac and nasal duct, leading to stricture of the latter with its usual sequelæ.

Dr. Frothingham said: I have been much interested in the paper and the discussion which it has elicited. I have no personal experience with the use of jequirity, and for that reason am, perhaps, more interested in hearing the experience of others. I was deterred from the use of this remedy by the disastrous effects that I saw reported by competent and reliable men soon after its introduction. To cite a single example, we may recall the published experience of Dr. Knapp of New York. Following as near as possible the rules for its use as originally given by De Wecker, he had unpleasant results. He then wrote Dr. De Wecker for an exact description of the class of cases in which it was useful, and to direct just how it should be used. De Wecker gave him explicit directions for its use. Dr. Knapp used it in accordance with these directions. As a re- 
sult he very nearly lost both eyes of a patient he thus treated, and that, too, in his own hospital, where the patient was under his direct observation and control. I have seen more patients that have been injured by jequirity than $I$ have seen benefited by its use, notwithstanding occasional brilliant results may be obtained through its action. One distressing case came to my notice. The case was that of the wife of a wealthy ranchman in Nevada. She had trachoma, but could see quite well with either eye. An Eastern oculist became the guest of her husband while on a Western tour. He treated her during his visit, and on his return home sent some jequirity with full directions for its use. It excited a severe inflammation, and both eyes were lost by panoph. thalmitis. She consulted first an oculist at Salt Lake City, and then came to me. Her case was that of hopeless blindness. It is this excessive inflammatory reaction, reported from its early use, that deterred me from resorting to it in practice. I felt that a remedy must be unsafe, and occasionally uncontrollable, which in a few hours after its application would cause the lids to be so swollen as to completely close the eyes, produce intense constitutional reaction, with a temperature sometimes reaching $104^{\circ}$. I have thought it prudent to wait until rules could be formulated for its use so that any practitioner could apply it with confidence. I am always suspicious of a remedy which, though some may use with uniform success, others, though faithfully following directions, cannot use without frequent disasters. As yet I have seen no sufficient evidence to establish the claim of jequirity as a safe remedy, and I regard its application as limited to a few peculiar cases of extreme pannus in which other and safer remedies have failed to afford relief.

Dr. X. C. Scot't, of Ohio, said: I am surprised at the remarks of my good friend from Michigan (Dr. Frothingham), for his experience is exactly opposite to mine. In a large number of cases the results have been most satisfactory. In only two cases has there been slight ulceration of the cornea, and these two cases were cured without leaving any trace of opacity behind. Jequirity is one of the greatest boons to patients suffering from trachoma with pannus, for with this remedy these cases can be cured by from onefourth to one-third of the time required by the former and usual mode of treatment. The plan of treatment seems much preferable to the stumpy tooth brush recommended by the gentleman from Tennessee (Dr. Savage). In the treatment of these cases I have used an infusion of the bean to which has been added some boracic acid. It should not be trusted in the hands of the patients to use, but should be applied by the surgeon himself. With the proper employment of jequirity cases of pannus can be cured that cannot be helped by any other method. After the acute inflamma- tory symptoms have disappeared I assist the good effects obtained from jequirity by continuing a mild astringent until the cure is completed.

Dr. Frank Trester SuITH, of Chattanooga, suggested that in the use of new remedies cases be taken where the condition is nearly the same in both eyes, and that the remedy be used in one eye and standard remedies be used in the other; then we would have something on which to base conclusions. He had observed the cases of Knapp and was perhaps prejudiced against jequirity, and thought that a remedy that had produced so much damage should be used only by those well qualified to treat all cases of eye disease. It certainly should not be used by the general practitioner.

DR. MINNEY: Is your success so much greater, Drs. Cheatham and Scott, since your use of jequirity, than in the same class of cases in your practice before its use?

Dr. Murrei,L: Dr. Mittendorf used powdered jequirity seven or eight years ago in proof of the power residing in the bean and not due to bacteria in the infusion. Iritis unquestionably follows its use. Never had iritis when he used atropine at the same time.

DR. FultoN said: With such a dangerous remedy as jequirity it is not safe to permit the patient to use it except under observation of an oculist. That the most brilliant results he had ever experienced in ophthalmology had been produced by the judicious application of this remedy. It should never be applied when there is any mucous or muco-purulent discharge.

Dr. Savage said: On the papers read by Drs. Cheatham and Murrell I want to speak of a plan of treatment which may be resorted to at a time when none of us would dare use jequirity, viz.: when there is no pannus. But whether the trachomatous condition is recent or old the conjunctiva may be cocainized and the brush treatment applied. I follow the Roumanian plan of preparing the brush. 'I buy an ordinary tooth brush of good quality and cut the bristles at the end of the brush to the length of one-eighth of an inch. With these short bristles I plow out the trachomatous bodies and smooth down the enlarged papilla. Very simple after-treatment is needed. This plan is far superior to either the use of jequirity, sulphate of copper or nitrate of silver. My experience with the brush, however, covers only twelve or fifteen cases.

Dr. TILLEY, of Chicago, said he was glad that Dr. Cheatham brought forward the subject of trachoma, as he thought that jequirity was an abused remedy. He had never seen powder so well prepared as the sample presented. Relative to the statement of Dr. Murrell that the active principle of the jequirity bean had never been isolated, this was a mistake-that according to his recollection it was reported in Merck's Bulletin; also that Samuelson, of Copenhagen, had isolated it in his 
preparations for a paper before the International Medical Congress at Copenhagen.

Dr. J. H. Thompson said: If pannus is dependent upon the deposit of inflammatory material in the substance of the cornea under Bowman's membrane, I cannot see how jequirity inflammation can clear up totally that membrane. Pannus will very frequently clear up under copper, even when there is no progressive disease on the lids (cicatricial transformation). The drug is excellent to alter the elements of an inflammation of the conjunctiva (chronic blenorrhœa, trachoma) so that the usual remedies may be efficient, when before neither nitrate of silver or copper would have any effect.

In answer to questions asked Dr Cheatham said: The inflammation resulting from the use of jequirity powder is controllable by means of hot carbolized water baths. By their use the in. flammation can be checked in a short time. Success from the use of jequirity powder in pannus is better than from other treatment, as it is more rapid; it cures cases in which all other treatment has failed; many cases have been cured by its use which would have been blind all their lives but for it. I make a second application if needed, as soon as all reaction from the first has subsided.

DR. WM. Dickinson, of St. Louis, inquired the mode of preparation of the specimen of powdered jequirity presented, and was told to pulverize the bean and sift it several times. He went on to say that he had used jequirity with most excellent results; in no cases had he experienced ill consequences.

DR. POLIAK, of St. Louis, in about I5o successive cases several years since, reported that in only one case did serious results follow. It is a most potent agent and is by no means to be emploved by laymen nor by any one who is not well informed in its use. He makes an aqueous solution, and after twenty-four hours this is strained or filtered and used intelligently by the ophthalmic surgeon himself.

DR. A. R. BAkER, of Cleveland, O., said: As this seems to be an experience meeting I wish to put my experience in the use of jequirity on record. Soon after the introduction of this remedy I met a case of granular lids with pannus. I brushed the lid with jequirity, which resulted in a violent panophthalmitis, and notwithstanding the use of hot water the eye went on to complete destruction. This unfortunate experience has caused me to use the remedy with great care. Yet I have had good results from its use in some cases. One of the most satisfactory was that of a physician who contracted a granular ophthalmia resulting in a dense pannus. In four years he was obliged to give up his practice and spent much time and money, even. going abroad for treatment without the least benefit. But since using jequirity he has been able to resume his practice, and enjoys very good vision.

\section{MEDICAL PROGRESS.}

The Influence of Menstruation on LacTATION. - The question whether a menstruating mother should continue to nurse her child, has been answered differently by many writers ; some say it alters the quantity of milk, others the quality, and still others both quantity and quality. N. Davis, Vernois and,Becquerel and Emil Pfeiffei alone have considered this matter scientifically. Schlichter (Wien. Klin. Wochenschr., ii, 5I, 52, I $889 ;$ iii, $4-5$, I 890 ), has attempted to add some needed observations in this direction. The analysis of the milk, which consisted of the determination of the fat, casein, total albumen, and total solids, gave in the milk of nine mothers no difference in the quality when menstruating; indeed the differences were less than normally occurred at different periods of the same day.

The children of fifty nursing mothers, who menstruated within two and one-half months of their confinement, were examined as to their weight and general condition, and no material change was found during, or just after the period of menstruation. The author sets forth the results of his observations, as follows: That after the sixth week, menstruation does no harm to to mother or child. Before the sixth week, hæmorrhage or menstruation retards the growth of the child. An outbreak of colic, dyspepsia, or enteritis during menstruation, is to be regarded as a mere coincidence and should not be treated by changing the nurse, but by the usual methods.

The Diagnostic and Prognostic Value of Urobilinuria. - Hayem (Gaz. Hebd., xxxvi) claims the same diagnostic value for urinalysis in diseases of the liver as in diseases of the kidney. While in the latter case we are on the look-out for albuminuric acid, etc., in the other the color ing matters are the ones to be considered. As no urobilin is found in the urine of healthy ani. mals, Hayem concludes that urobilinuria always means a disturbance of the liver. That the condition is so frequently found is due to improper diet and the use of alcohol. The degree of urobilinuria is an index of the gravity of the liver changes. While with light drinkers the quantity of urobilin is small and may completely disappear from the urine, in those of persistent free urcbilinuria, with a history of alcoholic excesses, we certainly have to do with a cirrhotic liver. The importance of this symptom is apparent when we think that it occurs early, long before other signs appear.

Treatment of Chronic GonorrheaA. FleINER (München Med. Wochenschr., xxxvi, I 889) recommends the following modifications of Unna's ointment sounds: The salve composed 